\title{
Iliopsoas abscess caused by chronic urolithiasis and pyelonephritis
}

\author{
Ayami Kawamoto, ${ }^{1}$ Ryota Sato, ${ }^{1}$ Kuniko Takahashi, ${ }^{1}$ Sarah Kyuragi Luthe ${ }^{2}$
}

${ }^{1}$ Department of Emergency and Critical Care, Urasoe General Hospital, Urasoe, Japan ${ }^{2}$ Department of Anesthesia, Urasoe General Hospital, Urasoe, Japan

\section{Correspondence to} Dr Ryota Sato, st051035@gmail.com

Accepted 29 November 2016
CrossMark

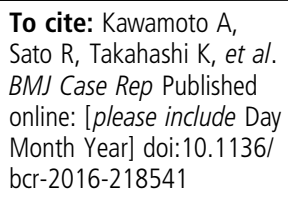

\section{DESCRIPTION}

A man aged 45 years, with a history of recurrent urolithiasis and pyelonephritis, presented with a 3-month history of fever. Physical examination revealed a nodule in his right inguinal area. CT with contrast showed a right iliopsoas abscess that extended to the inguinal area and a right urethral stone (figure 1). Drainage under fluoroscopic guidance was performed, and the contrast was injected into the cavity from the drainage tube to assess the abscess cavity. The contrast study demonstrated a connection between the urethra and abscess cavity (figure 2). The patient was administered $1 \mathrm{~g}$ cefotiam every 8 hours. Blood, urine and fluid cultures from the abscess were positive for Escherichia coli. Surgical drainage and right nephrectomy was performed. The patient was discharged 3 months after the surgery without any complication. The penetration of an iliopsoas abscess into the urinary tract is extremely rare, while the symptoms present in various ways. An iliopsoas abscess can be classified as primary or secondary. In general, secondary iliopsoas abscess occurs as a result of direct expansion of a nearby infection into the iliopsoas. ${ }^{1}$ Therefore, we believe this abscess was formed secondary to chronic urolithiasis and pyelonephritis. To suspect an iliopsoas abscess, physicians must be aware of the underlying conditions such as recurrent urolithiasis and urinary tract infections, which can lead to the pathogenesis of the abscess.

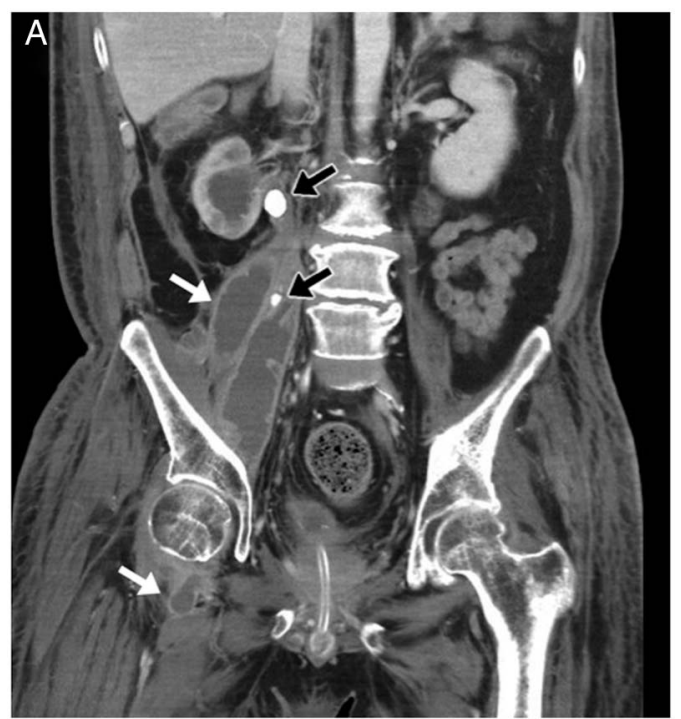

Figure 1 Contrast CT scan revealed a right iliopsoas abscess extending to the inguinal and a right urolithiasis.

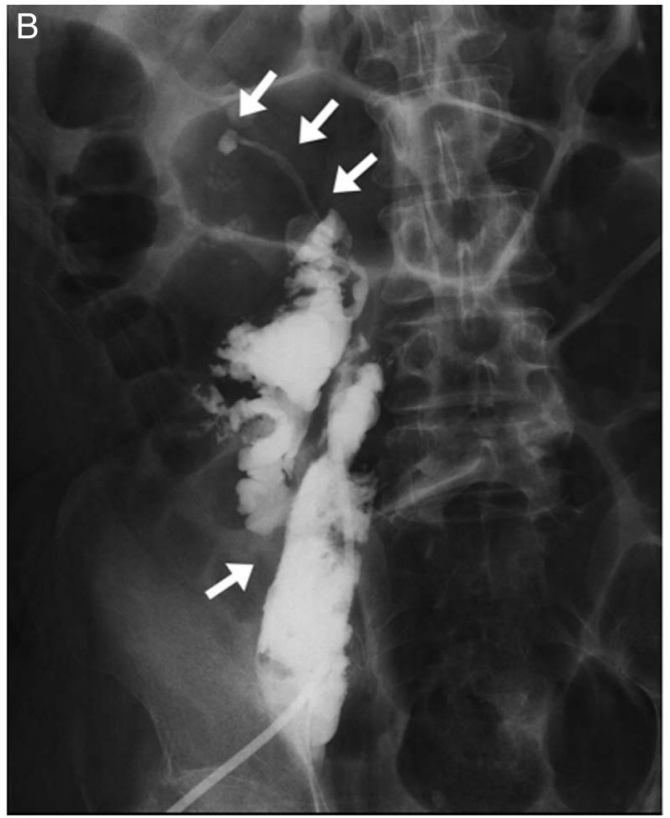

Figure 2 Injection of contrast from the drainage tube demonstrated a connection between the ureter and abscess cavity.

\section{Learning points}

- Recurrent urolithiasis and urinary tract infections can cause iliopsoas abscess penetrating into the urinary tract.

- In patients with recurrent urinary tract infections, physicians need to evaluate anatomical abnormalities by imaging tests.

Contributors All of these authors can access to all information. $A K$ and $K T$ have experienced this case and wrote the manuscript under supervision by RS and SKL.

Competing interests None declared.

Patient consent Obtained.

Provenance and peer review Not commissioned; externally peer reviewed.

\section{REFERENCE}

1 Shields D, Robinson P, Crowley TP. Iliopsoas abscess - a review and update on the literature. Int J Surg 2012;10:466-9. 
Copyright 2016 BMJ Publishing Group. All rights reserved. For permission to reuse any of this content visit http://group.bmj.com/group/rights-licensing/permissions.

BMJ Case Report Fellows may re-use this article for personal use and teaching without any further permission.

Become a Fellow of BMJ Case Reports today and you can:

- Submit as many cases as you like

- Enjoy fast sympathetic peer review and rapid publication of accepted articles

- Access all the published articles

- Re-use any of the published material for personal use and teaching without further permission

For information on Institutional Fellowships contact consortiasales@bmjgroup.com

Visit casereports.bmj.com for more articles like this and to become a Fellow 